\title{
Evaluation of the Association between Gastrointestinal Symptoms and Laboratory Outcomes in Hospitalized COVID-19 Patients
}

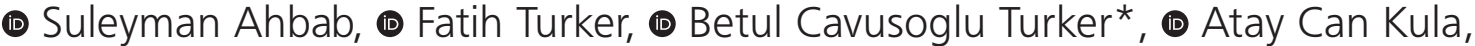 \\ ๑ Fatma Pinar Ziyadanoglu, ๑ Pelin Acar, ๑ Elif Ceren Ak, ๑ Raife Dilhan Alcelik, \\ (- Mufide Aydogan Ahbab**, ${ }^{*}$ Hayriye Esra Ataoglu \\ University of Health Sciences Turkey, Istanbul Haseki Training and Research Hospital, Clinic of Internal Medicine Clinic, Istanbul, Turkey \\ *Taksim Training and Research Hospital, Clinic of Internal Medicine Clinic, Istanbul, Turkey \\ **University of Health Sciences Turkey, Hamidiye Vocational School of Health Services, Istanbul, Turkey
}

\section{Abstract}

\begin{abstract}
Aim: The severe acute respiratory syndrome novel corona virus-2 (SARS-nCoV-2) which is an enveloped RNA virus was defined as the cause of Corona Virus Disease-2019 (COVID-19). Gastrointestinal (GI) symptoms can also be observed in COVID-19 patients. This study was performed to evaluate the association between $\mathrm{Gl}$ symptoms and laboratory results.

Methods: This retrospective study was carried out in the University of Health Sciences Turkey, Istanbul Haseki Health Training and Research Hospital between $11^{\text {th }}$ March and 1st June 2020. This study consisted of a total of 159 patients with COVID-19. COVID-19 infection was defined via a positive nasal and pharyngeal swab test. All symptoms of patients were recorded. Study patients were divided into 2 groups according to the presence of GI symptoms or not.

Results: There were 41 patients in the group with GI and 118 were in the group without Gl symptoms. Nausea and/or vomiting were observed in 29, diarrhea in 20 and abdominal pain in 10 patients. Percentages of anosmia (loss of smell sense) and ageusia (loss of taste sense) increased in patients with GI symptoms than the other group ( $p=0.005$ and $<0.0001)$. The mean serum aspartate amino transferase (AST) level elevated in COVID-19 patients with GI symptoms ( $p=0.022)$.
\end{abstract}

Conclusion: Anosmia and ageusia increased significantly in COVID-19 patients with GI. Serum C-reactive protein and AST levels statistically increased in COVID-19 patients with GI.

Keywords: Gastrointestinal symptoms, SARS-nCoV-2, coronavirus disease-2019, laboratory

\section{Introduction}

The severe acute respiratory syndrome novel corona virus-2 (SARS-nCoV-2) which is a single-stranded enveloped RNA virus was declared as the cause of Coronavirus disease-2019 (COVID-19) pandemic by the World Health Organization (1). COVID-19 which first appeared in Wuhan, China continues to affect the world caused deaths of more than 800,000 infected patients globally (2). Respiratory symptoms as cough, expectoration, sore throat and shortness of breath occur commonly in COVID-19 patients and can lead to various clinical results from pneumonia to acute respiratory distress syndrome, respiratory failure and mortality (3). Angiotensinconverting enzyme 2 (ACE2) is a metallopeptidase located on the surface of the cellular membrane and has an important role in the pathogenesis of the infection. SARS$\mathrm{nCOV}-2$ specifically recognizes and binds to ACE2 by using its spike protein with a high affinity which is responsible for the virus invasion (4). Moreover, ACE2 is expressed in many organs especially in the lung tissue, nasopharyngeal mucosa, small intestine, colon, vascular endothelium and liver (5). In addition to the inflammatory parameters of laboratory analysis, radiological imaging as chest computed tomography $(\mathrm{CT})$ is also a useful way to detect pulmonary

Address for Correspondence: Betul Cavusoglu Turker, Taksim Training and Research Hospital, Clinic of Internal Medicine Clinic, Istanbul, Turkey 
involvement of the infection. According to recent clinical observations, gastrointestinal (Gl) symptoms such as nausea and/or vomiting, abdominal pain and diarrhea may occur in COVID-19 patients without respiratory and other constitutional symptoms (6-8). Patients with Gl symptoms may reflect an elevated viral burden in these patients compared to those with only respiratory symptoms (9). It is important to take into account that many COVID-19 patients may present Gl symptoms. The intestinal epithelial invasion by SARS-nCoV-2 may result in increased permeability and diminished barrier function with the presence of Gl symptoms (9). In this study, it was aimed to better evaluate associations of the clinical characteristics and laboratory results between patients with and without Gl symptoms.

\section{Methods}

\section{Study Design}

This retrospective study was carried out in the internal medicine inpatient clinic of the University of Health Sciences Turkey, Istanbul Haseki Health Training and Research Hospital between 11th March and 1st June 2020. The first official registered COVID-19 case was detected on 11th March 2020 in Istanbul, Turkey. University of Health Sciences Turkey, Istanbul Haseki Health Training Hospital has been designated as one of the pandemic center hospitals in Istanbul by the Turkish Ministry of Health. This study consisted of a total of 159 patients who admitted consecutively and hospitalized in the internal medicine clinic with suspected COVID-19. Patients with a positive clinical evaluation, biochemical tests and chest CT scan results were included in this study. Confirmed cases of COVID-19 infection were defined as with a positive nasal and pharyngeal swab test result from the laboratory (10). University of Health Sciences Turkey, Istanbul Haseki Training and Research Hospital's local Ethics Committee approved (registration no: 2020-62) the study design. Data for the study were derived from the electronic management system of the hospital. The database information was anonymized and approved by the ethics committee with no need for consent. Gl and other symptoms of the patients on the admission to the hospital were recorded before medical treatment. Other symptoms were fever $\left(\geq 38{ }^{\circ} \mathrm{C}\right)$, fatigue, muscle soreness, cough, sore throat, shortness of breath, anosmia (loss of smell sense), ageusia (loss of taste sense) and hemoptysis. Patients with Gl symptoms defined as those who have at least one of the symptoms; nausea and/or vomiting, abdominal pain and diarrhea (more than 3 times a day with loose stools) without a recent history of antibiotic use. Study patients were divided into 2 groups according to the presence of $\mathrm{Gl}$ symptoms and compared the laboratory findings. Intensive care unit (ICU) follow-up and mortality were determined as the primary endpoints in this study.

\section{Biochemical Analysis and Radiological CT Imaging}

The laboratory-confirmed COVID-19 based on real-time reverse transcriptase polymerase chain reaction assay for nasopharyngeal swab specimens. Complete blood counts, biochemical analysis and chest $\mathrm{CT}$ imaging were performed for all patients at the first admittance to the hospital. Complete blood counts were analyzed using the Sysmex XE 2100i device (Japan) by fluorescence flow cytometry. Biochemical parameters such as alanine aminotransferase (ALT), aspartate aminotransferase (AST), gamma-glutamyl transferase (GGT), alkaline phosphatase $(A L P)$, amylase, lipase, c-reactive protein (CRP), fibrinogen, D-dimer and ferritin were analyzed by using an Abbot Architect Analyzer System (IL, USA). Chest CT is an important method to detect COVID-19 related pulmonary lesions. Presence of bilateral involvement, ground-glass opacification, consolidation and pleural effusion findings were determined as the important findings on the chest CT scans for the possible pulmonary involvement (11). Chest CT scans were performed by using a 64-detector Philips Brilliance CT device (Philips Medical Systems, Cleveland, Ohio) and pulmonary involvement was examined. Study groups were compared according to the presence of other symptoms, laboratory parameters and chest CT results.

\section{Statistical Analysis}

Categorical variables were expressed as numbers and percentages. Study data were presented as the mean \pm standard deviation. SPSS 16.0 for Windows was used to perform statistical analysis. The distributions of variables were assessed by using the Kolmogorov-Smirnov z-test. T-tests were used to analyze normally distributed variables, and the Mann-Whitney $U$ test was used to analyze nonnormally distributed variables. A p-value less than 0.05 was considered statistically significant.

\section{Results}

This study consisted of 159 patients who diagnosed with COVID-19 based on nasopharyngeal swab specimens, biochemical analyses and chest CT image results. Study patients were classified according to their symptom characteristics. There were 41 patients in the group with $\mathrm{Gl}$ and 118 were in the group without Gl symptoms. Nausea and/or vomiting were found in 29 (70.7\%), loose stools in $20(48.8 \%)$ and abdominal pain in 10 (24.4\%) patients with $\mathrm{Gl}$ symptoms. A total of 150 patients were recovered, 3 patients were lost and 6 patients were followed up in intensive care unit. The median age of patients with Gl symptoms was 57 [minimum-maximum (min: 27-max: 81)] and without Gl symptoms was 55 
(min: 18-max: 91) years. Percentages of sore throat, anosmia and ageusia sense significantly elevated in patients with Gl symptoms than the other group ( $p=0.035,0.005$ and $<0.0001$ ) as indicated in Table 1 . The mean serum AST level significantly increased in patients with $\mathrm{Gl}$ symptoms $(p=0.022)$. Platelet and CRP levels were found to be significantly higher in patients with Gl symptoms than those without (Table 2). Although serum ALT and amylase levels increased in patients with $\mathrm{Gl}$ symptoms than others, no statistical significance was observed. According to the results of chest CT scans, percentage of pulmonary consolidation was found statistically increased in patients with $\mathrm{Gl}$ symptoms $(\mathrm{p}<0.0001)$.

\section{Discussion}

Gl symptoms are common observed in COVID-19 patients besides respiratory symptoms. These symptoms due to SARS-CoV-2 may be associated with invaded ACE2 expressing enterocytes in the small intestine, ileum and colon. GI system may be a potential route for SARS-CoV-2 infection and can explain the occurrence of GI symptoms (12). However ACE2 receptors are expressed diffusely on the mucous membrane of the whole oral cavity, particularly on the tongue (13), anosmia and ageusia may represent the first or only symptomatic manifestation of COVID-19 in Gl system (14). In this study, anosmia and ageusia sense significantly increased in COVID-19 patients with $\mathrm{Gl}$ symptoms. Likewise, we observed these sensory impairments as complete and sudden onset of anosmia and ageusia in the study patients. Patients with acute onset loss of smell and taste are considered that may have a close relation for concomitant SARS-CoV-2 infection (15). The mechanism of olfaction impairment by COVID-19 is not clarified. The possible hypotheses of anosmia can be related to direct viral damage of the olfactory sensory neurons and systemic inflammation (16-18). Furthermore, SARS-CoV-2 could occupy the taste buds on the tongue accelerating the degradation of the gustatory particles (19). Leichen et al. (20) reported that anosmia and ageusia were independently and strongly associated with a positive COVID-19 test. The recovery of smell and taste senses lasts for the first two weeks after the resolution of COVID-19 (20). In patients with COVID-19, anosmia is not usually accompanied by nasal obstruction unlike other causes of upper respiratory viral infections (21). In addition, ACE2 expression is higher in the small intestine, duodenum and colon. Patients with digestive symptoms have more viruses in the gut-based

\begin{tabular}{|c|c|c|c|}
\hline Characteristics & With GI symptoms $(n=41)$ & Without GI symptoms $(n=118)$ & $\mathbf{p}$ \\
\hline Age, median (min-max) & $57(27-81)$ & $55(18-91)$ & 0.774 \\
\hline Gender (F/M) & $28 / 13$ & $62 / 56$ & 0.080 \\
\hline Fever†, n (\%) & $22 / 41(53.7 \%)$ & $54 / 118(45.8 \%)$ & 0.383 \\
\hline Fatigue ${ }^{\dagger}, \mathrm{n}(\%)$ & $23 / 41(56.1 \%)$ & $56 / 118(47.5 \%)$ & 0.130 \\
\hline Muscle sorenesst, n (\%) & $13 / 41(31.7 \%)$ & $22 / 118(18.8 \%)$ & 0.087 \\
\hline Cought, n (\%) & $25 / 41(61.0 \%)$ & $61 / 118(52.1 \%)$ & 0.328 \\
\hline Sore throat ${ }^{\dagger}, \mathrm{n}(\%)$ & $11 / 41(26.8 \%)$ & $15 / 118(12.7 \%)$ & 0.035 \\
\hline Shortness of breath $\dagger, \mathrm{n}(\%)$ & $15 / 41(37.5 \%)$ & 40/118 (33.9\%) & 0,679 \\
\hline Anosmiat, n (\%) & $5 / 41(12.2 \%)$ & $2 / 118(1.7 \%)$ & 0.005 \\
\hline Ageusiat, n (\%) & $8 / 41(19.5 \%)$ & $3 / 118(2.6 \%)$ & $<0.0001$ \\
\hline Hemoptysis†, n (\%) & $1 / 41(2.4 \%)$ & $2 / 118(1.7 \%)$ & 0.763 \\
\hline \multicolumn{4}{|l|}{ Co-morbidities } \\
\hline Diabetes mellitus, n (\%) & $8 / 41(19.5 \%)$ & $40 / 118(33.9 \%)$ & 0.084 \\
\hline Hypertension, n (\%) & $23 / 41(56.1 \%)$ & $43 / 118(37.1 \%)$ & 0.034 \\
\hline Chronic heart disease, n (\%) & $6 / 41(14.6 \%)$ & $21 / 118(18.1 \%)$ & 0.613 \\
\hline Chronic lung disease, n (\%) & $4 / 41(9.8 \%)$ & $13 / 118(11 \%)$ & 0.822 \\
\hline Chronic kidney disease, n (\%) & $1 / 41(2.4 \%)$ & $6 / 118(5.1 \%)$ & 0.477 \\
\hline Hospitalization days, median (min-max) & $9(1-20)$ & $8(3-28)$ & 0.224 \\
\hline \multicolumn{3}{|l|}{ Primary endpoints } & \multirow{4}{*}{0.235} \\
\hline ICU follow up, n (\%) & $1 / 41(2.4 \%)$ & $5 / 118(4.2 \%)$ & \\
\hline Mortality, n (\%) & $2 / 41(4.8 \%)$ & $1 / 118(0.8 \%)$ & \\
\hline Total, n (\%) & $3 / 41(7.3 \%)$ & $6 / 118(5.1 \%)$ & \\
\hline
\end{tabular}




\begin{tabular}{|c|c|c|c|}
\hline Parameters (normal ranges) & $\begin{array}{l}\text { With GI Symptoms } \\
(n=41)\end{array}$ & Without GI Symptoms ( $n=118)$ & $\mathbf{p}$ \\
\hline Leukocyte (4.2-10.2×103/uL) & $7.17 \pm 5.41$ & $6.97 \pm 3.02$ & 0.275 \\
\hline 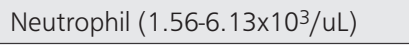 & $4.37 \pm 2.30$ & $4.64 \pm 2.59$ & 0.550 \\
\hline 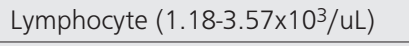 & $1.59 \pm 0.60$ & $1.64 \pm 0.89$ & 0.704 \\
\hline Hemoglobin (12-16 g/dL) & $12.81 \pm 1.59$ & $12.63 \pm 1.96$ & 0.575 \\
\hline 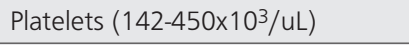 & $248.51 \pm 112.79$ & $213.20 \pm 68.66$ & 0.019 \\
\hline MPV (6.8-10.8 fL) & $10.50 \pm 1.11$ & $10.90 \pm 1.18$ & 0.081 \\
\hline CRP (0-5 mg/L) & $68.54 \pm 77.83$ & $45.62 \pm 52.49$ & 0.037 \\
\hline Procalcitonin (0-0.06 ng/mL) & $0.22 \pm 0.87$ & $0.19 \pm 0.51$ & 0.844 \\
\hline Fibrinogen (180-350 mg/dL) & $382.09 \pm 206.00$ & $350.69 \pm 221.05$ & 0.366 \\
\hline D-dimer $(<0.55 \mathrm{mg} / \mathrm{L})$ & $1.71 \pm 2.87$ & $1.22 \pm 2.79$ & 0.159 \\
\hline Ferritin $(11-306 \mathrm{ng} / \mathrm{mL})$ & $235.03 \pm 223.73$ & $279.37 \pm 354.71$ & 0.539 \\
\hline Albumin $(35-52 \mathrm{~g} / \mathrm{dL})$ & $35.70 \pm 6.08$ & $36.43 \pm 4.49$ & 0.460 \\
\hline LDH (120-247 U/L) & $298.84 \pm 125.48$ & $253.15 \pm 143.00$ & 0.092 \\
\hline AST $(<35 \mathrm{U} / \mathrm{L})$ & $45.80 \pm 46.59$ & $32.27 \pm 23.81$ & 0.022 \\
\hline $\operatorname{ALT}(<35 \mathrm{U} / \mathrm{L})$ & $36.57 \pm 54.56$ & $26.39 \pm 21.53$ & 0.093 \\
\hline GGT $(<38 \mathrm{U} / \mathrm{L})$ & $51.24 \pm 47.50$ & $56.23 \pm 84.29$ & 0.744 \\
\hline $\operatorname{ALP}(30-120 \mathrm{U} / \mathrm{L})$ & $105.42 \pm 141.00$ & $104.01 \pm 131.75$ & 0.931 \\
\hline Amylase (28-100 U/L) & $92.86 \pm 65.29$ & $73.93 \pm 55.06$ & 0.089 \\
\hline Lipase $(<67 \mathrm{U} / \mathrm{L})$ & $46.76 \pm 36.52$ & $42.25 \pm 41.62$ & 0.325 \\
\hline \multicolumn{4}{|l|}{ Chest CT scan findings } \\
\hline Bilateral involvement, n (\%) & $35 / 41(85.4 \%)$ & $86 / 118(72.9 \%)$ & 0.106 \\
\hline Ground-glass opacification, n (\%) & $30 / 41(73.2 \%)$ & $94 / 118(79.7 \%)$ & 0.388 \\
\hline Pulmonary consolidation, n (\%) & $24 / 41(58.5 \%)$ & $28 / 118(23.7 \%)$ & $<0.0001$ \\
\hline Pleural effusion, n (\%) & $1 / 41(2.4 \%)$ & $10 / 118(8.5 \%)$ & 0.190 \\
\hline
\end{tabular}

on the stool RNA testing of SARS-CoV-2 results and thus potentially greater opportunity to suffer direct damage on the gut mucosa (22).

In this study, serum CRP and AST levels were found statistically higher in patients with GI symptoms than in other patients. Zhang et al. (23) reported elevated liver enzymes in approximately $15-50 \%$ of infected patients with COVID-19. Jin et al. (24) demonstrated significantly increased AST levels in COVID-19 patients with GI symptoms as an indicator for liver injury. Elevated ALT levels have also reported without acute liver failure in COVID-19 patients (25). Although there was an increase in serum ALT in patients with Gl symptoms, statistical significance could not be achieved in this study. Agarwal et al. (26) reported that liver transaminases elevated mildly in many patients with COVID-19. An increase in the levels of liver enzymes in infected patients may be related to ACE2 receptors located on cholangiocytes and hepatocytes (26). Pancreatic islet cells potentially implicate the high level of ACE2 receptor expression and abnormalities in serum pancreatic enzyme levels may be observed in some cases (27). Although Wang et al. (28) reported serum pancreatic enzyme elevations in 9 of 52 patients with COVID-19, no case was observed with severe pancreatitis. In accordance with Wang et al. (28), serum amylase levels in patients with Gl symptoms were found to be elevated compared to other group in this study, statistical significance was not achieved ( $p=0.089$ ).

\section{Study Limitations}

This study has some limitations. First, this study was performed with COVID-19 patients who necessitate to be treated by being hospitalized in the internal medicine clinic. The study was conducted with a limited sample size and limited time interval. It will be beneficial to perform further studies to be conducted with a larger number of participants to verify and relate the results obtained from this study. Serological antibody tests for all participants and virus RNA investigations in the stool for patients with 
Gl symptoms were not applied. By this, it was unable to evaluate correlations between $\mathrm{Gl}$ symptoms and viral burden. In addition, the duration of symptoms and transmission ways of the infection could not be clearly obtained for all patients.

\section{Conclusion}

Gl symptoms are common in COVID-19 patients. Anosmia and ageusia were important findings and observed proportionally higher in patients with GI symptoms at the onset of COVID-19. In addition, serum AST levels were found statistically elevated in COVID-19 patients with GI symptoms than those without. Increased serum AST levels in patients with Gl symptoms may be considered as an indicator for the enteric involvement of SARS-Cov-2.

\section{Author Contributions}

Concept: S.A., Design: F.T., Data Collection or Processing: P.A., F.P.Z., E.C.A., R.D.A., A.C.K., Analysis or Interpretation: M.A.A., H.E.A., Literature Search: B.C.T., Writing: S.A.

Conflict of Interest: The authors declared no conflicts of interest with respect to the authorship and/or publication of this article

Financial Disclosure: The authors received no financial support for the research and/or authorship of this article.

\section{References}

1. Lu R, Zhao X, Li J, et al. Genomic characterisation and epidemiology of 2019 novel coronavirus: implications for virus origins and receptor binding. Lancet 2020;395:565-74.

2. Xu C, Dong $Y, Y u X$, et al. Estimation of reproduction numbers of COVID-19 in typical countries and epidemic trends under different prevention and control scenarios. Front Med 2020;14:613-22.

3. Li Q, Guan X, Wu P, et al. Early Transmission Dynamics in Wuhan, China, of Novel Coronavirus-Infected Pneumonia. N Engl J Med 2020;382:1199-207.

4. Wan Y, Shang J, Graham R, Baric RS, Li F. Receptor Recognition by the Novel Coronavirus from Wuhan: an Analysis Based on Decade-Long Structural Studies of SARS Coronavirus. J Virol 2020;94:127-20.

5. Hamming I, Timens $W$, Bulthuis ML, Lely AT, Navis G, van Goor $\mathrm{H}$. Tissue distribution of ACE2 protein, the functional receptor for SARS coronavirus. A first step in understanding SARS pathogenesis. J Pathol 2004;203:631-7.

6. Huang $C$, Wang $Y$, Li $X$, et al. Clinical features of patients infected with 2019 novel coronavirus in Wuhan, China. Lancet 2020;395:497-506.

7. Guan WJ, Ni ZY, Hu Y, et al. Clinical Characteristics of Coronavirus Disease 2019 in China. N Engl J Med 2020;382:1708-20.
8. Chen N, Zhou M, Dong X, et al. Epidemiological and clinical characteristics of 99 cases of 2019 novel coronavirus pneumonia in Wuhan, China: a descriptive study. Lancet 2020;395:507-13.

9. Gu J, Han B, Wang J. COVID-19: Gastrointestinal Manifestations and Potential Fecal-Oral Transmission. Gastroenterology 2020;158:1518-9.

10. WHO. Laboratory testing for 2019 novel coronavirus in suspected human cases. Interim guidance January 17,2020. Available from: https://apps.who.int/iris/bitstream/ handle/10665/332300/WHO-2019-nCoV-laboratory-2020.2eng.pdf

11. Chung M, Bernheim A, Mei X, et al. CT Imaging Features of 2019 Novel Coronavirus (2019-nCoV). Radiology 2020;295:202-7.

12. Luo S, Zhang $X, X u H$. Don't Overlook Digestive Symptoms in Patients With 2019 Novel Coronavirus Disease (COVID-19). Clin Gastroenterol Hepatol 2020;18:1636-7.

13. Xu H, Zhong L, Deng J, et al. High expression of ACE2 receptor of 2019-nCoV on the epithelial cells of oral mucosa. Int J Oral Sci 2020;12:8.

14. Vaira LA, Salzano G, Deiana G, De Riu G. Anosmia and Ageusia: Common Findings in COVID-19 Patients. Laryngoscope 2020;130:1787.

15. Xydakis MS, Dehgani-Mobaraki P, Holbrook EH, et al. Smell and taste dysfunction in patients with COVID-19. Lancet Infect Dis 2020;20:1015-6.

16. Baig AM, Khaleeq A, Ali U, Syeda H. Evidence of the COVID-19 Virus Targeting the CNS: Tissue Distribution, HostVirus Interaction, and Proposed Neurotropic Mechanisms. ACS Chem Neurosci 2020;11:995-8.

17. Kern RC, Conley DB, Haines GK 3rd, Robinson AM. Pathology of the olfactory mucosa: implications for the treatment of olfactory dysfunction. Laryngoscope 2004;114:279-85.

18. Gilani S, Roditi R, Naraghi M. COVID-19 and anosmia in Tehran, Iran. Med Hypotheses 2020;141:109757.

19. Vaira LA, Salzano G, Fois AG, Piombino P, Riu GD. Potential pathogenesis of ageusia and anosmia in COV ID-19 patients. Int Forum Allergy Rhinol 2020;10:1103-4.

20. Lechien JR, Chiesa-Estomba CM, De Siati DR, et al. Olfactory and gustatory dysfunctions as a clinical presentation of mildto-moderate forms of the coronavirus disease (COVID-19): a multicenter European study. Eur Arch Otorhinolaryngol 2020;277:2251-61.

21. Eliezer $M$, Hautefort $C$, Hamel $A L$, et al. Sudden and Complete Olfactory Loss of Function as a Possible Symptom of COVID-19. JAMA Otolaryngol Head Neck Surg 2020;146:674-5.

22. Han C, Duan C, Zhang S, et al. Digestive Symptoms in COVID-19 Patients With Mild Disease Severity: Clinical Presentation, Stool Viral RNA Testing, and Outcomes. Am J Gastroenterol 2020;115:916-23. 
23. Zhang C, Shi L, Wang FS. Liver injury in COVID-19: management and challenges. Lancet Gastroenterol Hepatol 2020;5:428-30.

24. Jin X, Lian JS, Hu JH, et al. Epidemiological, clinical and virological characteristics of 74 cases of coronavirus-infected disease 2019 (COVID-19) with gastrointestinal symptoms. Gut 2020;69:1002-9.

25. Xu XW, Wu XX, Jiang XG, et al. Clinical findings in a group of patients infected with the 2019 novel coronavirus (SARSCov-2) outside of Wuhan, China: retrospective case series. BMJ 2020;368:606.
26. Agarwal A, Chen A, Ravindran N, To C, Thuluvath PJ. Gastrointestinal and Liver Manifestations of COVID-19. J Clin Exp Hepatol 2020;10:263-5.

27. Aroniadis OC, DiMaio CJ, Dixon RE, et al. Current Knowledge and Research Priorities in the Digestive Manifestations of COVID-19. Clin Gastroenterol Hepatol 2020;18:1682-4.

28. Wang F, Wang H, Fan J, Zhang Y, Wang H, Zhao Q. Pancreatic Injury Patterns in Patients With Coronavirus Disease 19 Pneumonia. Gastroenterology 2020;159:367-70. 